\title{
Human Microbiota - How to Affect Them Properly?
}

\author{
Petr Ryšávka ${ }^{1,2 *}$, Jana Čmielová ${ }^{1}$ and Ivana Márová ${ }^{2}$ \\ ${ }^{1}$ Medi Pharma Vision Inc., Dobrovského 1310/64, 61200 Brno, Czech Republic \\ ${ }^{2}$ Faculty of Chemistry, Brno University of Technology, Purkyňova 464/118, 61200 Brno, Czech Republic \\ *Corresponding author: Petr Ryšávka, Medi Pharma Vision Inc., Brno, Czech Republic
}

\begin{tabular}{lll}
\hline ARTICLE INFO & & ABSTRACT \\
\cline { 1 - 1 } $\begin{array}{l}\text { Received: 幽 August 13, } 2021 \\
\text { Published: }\end{array}$ & & $\begin{array}{l}\text { Citation: Petr Ryšávka, Jana Čmielová, Ivana Márová. Human Microbiota - How to Affect } \\
\text { Them Properly?. Biomed J Sci \& Tech Res 38(3)-2021. BJSTR. MS.ID.006140. }\end{array}$ \\
\hline
\end{tabular}

\section{Introduction}

Human microbiome became the centre of general attention of a number of scientists across various fields of medicine and science in the last decade, because there is many evidence of connection among microbiota or dysbiosis of microbiota, development and modulation of some diseases process, i.e. obesity, acne vulgaris, atopic dermatitis, depression, Alzheimer's disease, etc. [1-3]. It must be said that regardless of a huge attention focused to microbiome, there is still only a little practical information efficiency and clear interpretation of these research due to the huge variability of microbiota and therefore high analytical challenging. However, it is undisputed that certain symbiosis exists between human body and microbiota and that activity of microbiota to human organism is more meaningful. The most attention is dedicated to the gut microbiome which is the biggest part of the whole human microbiome. Gut microbiotas affect not only digestion, but also immunological processes and its significance is enhanced by the gut-bran or gut-brain-skin axis [2,3].

Recent research suggests that not only the abundance of specific strains or their ratio, but also metabolic activity of microbiota has significant impact on human body. Studies also indicate that the Western diet or high-fat-high-sugar diet may lead to low-grade inflammation and dysbiosis. This disturbed state is consequently maintained through dysbiosis and through the delivery of the same energy source for microbiota that makes the change more inconvenient. Data confirm that infection with SARS-CoV-2 can change the intestinal microflora. The content of Lactobacillus, Streptococcus, Clostridium, and Bifidobacterium in the intestinal flora of patients with SARS-CoV-2 is relatively high, in contrast with low content of Bacteroidetes, Roseburia, Faecalibacterium, Coprococcus, and Parabacteroides. The imbalance of the intestinal flora may also cause symptoms of the central nervous system. In addition, probiotic intervention may improve the effectiveness of a vaccine, further preventing a virus infection [4]. Nowadays, the huge challenge is microbiota manipulation through oral or topical probiotics, prebiotics, cosmeceutics (skin microbiome-friendly ingredients) or postbiotics [5].

In the case of obesity, positive connection between consumption of prebiotics, probiotics (dairy products) and loss of body weight was demonstrated [6]. However, the lack of science evidence in this field exists. On the other hand, available studies differ in probiotic strains used, daily dose ( $\mathrm{CFU} / \mathrm{ml}$ ), time of application and that makes the conclusion and the real application more difficult. Another possibility is fecal microbiota transplantation (i.e., Clostridium difficile infection, recurrent ulcerative colitis) or transplantation of skin microbiota (i.e., atopic dermatitis), but these methods are limited and are quite demanding. The skin microbiome is of growing interest in the field of cosmetics, focusing on the exploitation of these proprieties to improve human wellbeing through various formulations, i.e., microbial-based active sunscreen compounds s.c. next-generation photoprotection products [7]. Many probiotic strains are used in various commercial products and its consumption is still arised. However, the question is are probiotics used properly and should probiotics act more efficient? The answear is very complex. 
Each individual person has unique microbiome composition with unique metabolic profile together with unique immune system. For example, ten people will have different responds to one probiotic mixture on the basis of their age, gender, BMI, diet, smoking, fecal microbiota composition, health, etc. The aim is to prepare the appropriate composition of probiotics for concrete person at present time on the basis of personal anamnesis and individual analysis of intestinal/fecal microbiome and to choose beneficial strains for concrete microbiome condition (i.e. production of folate, utilisation of lactose, etc.). A pilot study is now in process and the results seem to be very interesting. From our view, target and appropriate choice of beneficial strains for individual person provides the huge potential to improve efficiency of probiotics and thus to reduce intestinal dysbiosis. This approach may reduce certain disease symptoms and prevent some disease or its serious course, including Covid-19.

\section{References}

1. Martínez Cuesta MC, Del Campo R, Garriga García M, Peláez C, Requena $\mathrm{T}$ (2011) Taxonomic Characterization and Short-Chain Fatty Acids Production of the Obese Microbiota. Front Cell Inf Microbiol 11: 598093.

\section{ISSN: 2574-1241}

DOI: 10.26717/BJSTR.2021.38.006140

Petr Ryšávka. Biomed J Sci \& Tech Res

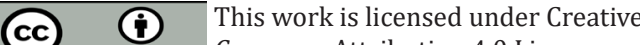

Submission Link: https://biomedres.us/submit-manuscript.php
2. Park DH, Kim JW, Park HJ, Hahm DH (2021) Comparative Analysis of the Microbiome across the Gut-Skin Axis in Atopic Dermatitis. Int J Mol Sci 22(8): 4228.

3. Wilkowska A, Szałach $Ł P$, Cubała WJ (2021) Gut Microbiota in Depression: A Focus on Ketamine. Front Behav Neurosci 15: 693362.

4. Xu J, Wu Z, Zhang M, Liu S, Zhou L, et al. (2021) The Role of the Gastrointestinal System in Neuroinvasion by SARS-CoV-2. Front Neurosci 15: 694446.

5. Boxberger M, Cenizo V, Cassir N, La Scola B (2021) Challenges in exploring and manipulating the human skin microbiome. Microbiome $9(1): 125$.

6. Sanchez M, Panahi S, Tremblay A (2014) Childhood obesity: a role for gut microbiota? Int J Environ Res Public Health 12(1): 162-175.

7. Souak D, Barreau M, Courtois A, André V, Duclairoir Poc C, et al. (2021) Challenging Cosmetic Innovation: The Skin Microbiota and Probiotics Protect the Skin from UV-Induced Damage. Microorganisms 9(5): 936.

BIOMEDICAL
RESEARCHES $\quad \begin{aligned} & \text { Assets of Publishing with us } \\ & \text { - Immediate, unrestricted online access }\end{aligned}$

